\title{
Making Price Elasticity A Useful Metric For Maximizing Profit
}

Ted Mitchell, University of Nevada, USA

Igor Makienko, University of Nevada, USA

Shawn Mitchell, Chessboard Communications, USA

\begin{abstract}
An estimate of a product's price elasticity can be used to calculate whether a price change will increase or decrease sales revenue. However, the price elasticity of demand does not indicate if a price change will increase or decrease gross profit because the marginal cost per unit confounds the calculation. However, an estimate of the price elasticity can be combined with the product's markup to calculate if a change in the selling price will increase or decrease the profit. The purpose of this paper is to demonstrate how estimates of the price elasticity and the markup can be combined to help managers decide if greater profits can be realized with a price decrease or a price increase.
\end{abstract}

Keywords: Price Elasticity; Gross Profit; Net Profit; Product Markup

\section{INTRODUCTION}

2 few minutes searching on the Internet will demonstrate that the concept of price elasticity is very much alive and kicking. There are hundreds of sites that offer definitions of and provide explanations about the price elasticity of demand. The vast majority of sites indicate that elasticity is a useful metric for people who manage everything from the individual business firm to the entire economy. Some of the information is accurate and some is inaccurate. For example, one site proclaimed, "Once you figure out what the price elasticity is for your product, you can figure out how to maximize your profits by either raising prices if the price is inelastic, or CUTTING prices to increase sales if the price is very elastic (wliki.answers.com)."

As a classroom exercise I took the above pronouncement as a lead-in to a lecture on the uses of price elasticity. I asked my students to solve the following questions:

I am a marketing manager selling a well-differentiated product. I have a selling price of $\$ 8$ per unit and my variable cost of manufacturing the product is $\$ 2$ per unit. The estimate of my current price elasticity at the current price is Eqp $=-4.0$.

1. Would a one dollar increase in the selling price have the effect of increasing or decreasing the total quantity of products being sold?

2. Would a one dollar increase in the selling price have the effect of increasing or decreasing the sales revenue?

3. Would a one dollar increase in the selling price have the effect of increasing or decreasing the gross profits?

My students rapidly discovered that it is very easy to find definitions of elasticity. However, they also learned that the examples of managers using price elasticity to set prices or adjust prices are very hard to find.

The students learned that there is an important difference between revenue and profit and that the price that maximizes revenue is seldom the price that maximizes profit. They reviewed many of the classical attributes associated with the price elasticity of demand. For example they learned the following: 
1. Price elasticity of demand is a value free index that allows us to compare the price sensitivity of different products across different markets.

2. Price elasticity of demand is interpreted as the percentage change in the total quantity, $\% \Delta \mathrm{Q}$, that will be sold for a one percentage change in the selling price, $\% \Delta \mathrm{P}$, (i.e., Eqp $=\% \Delta \mathrm{Q} / \% \Delta \mathrm{P}$ ).

3. When the price elasticity is negative, then an increase in price will decrease the quantity sold.

4. When the demand is price inelastic (i.e., $0>$ Eqp $>-1.0$ ), then a small price increase will increase the total revenue.

5. When the demand is price elastic (i.e., Eqp $<-1.0$ ), then a small price increase will decrease the revenue.

6. When the price elasticity of demand is equal to -1.0 , then the current price will maximize total revenue.

The students learned that with information that the current elasticity was Eqp $=-4.0$ they could answer some of the homework questions. For example:

1. A negative elasticity implies that an increase in the selling price will decrease the quantity sold.

2. A price elasticity of -4.0 implies that the price is on the elastic portion of the demand curve and an increase in the selling price will decrease the sales revenue.

However, the students could not establish the consequences of a price increase on profits. The Internet claim that with knowledge of the price elasticity "you can figure out how to maximize your profits" is very misleading. You can predict the consequences of small price changes on revenues and quantities sold but it is necessary to know more about the nature of the demand curve to establish the price that maximizes revenue, $\operatorname{Pr}^{*}$, or the price that maximizes profit, $\mathrm{Pz}^{*}$.

Price elasticity is presented in virtually every introductory textbook on marketing. The classic virtue of price elasticity to the marketing manager is that the magnitude of the elasticity provides a guide to making price adjustments that can increase revenue. However, the normal goal for marketing managers is to maximize profits, not revenues, and a move towards higher revenues does not necessarily lead to higher profits. When the price is on an inelastic portion of the demand, then elasticity correctly guides the manager to choose higher prices which result in higher revenues and higher profits. Unfortunately, elasticity is not a reliable guide to increased profits. For example when demand is elastic, there is a range of prices in which a price change that increases revenues results in lower profits!

When the demand is elastic a price increase will always decrease the quantity sold and decrease the total revenue. However, there is nothing about the size or direction of the elasticity that indicates when the profits will be increasing or decreasing.

In practice, price elasticity proves to be a very inadequate guide to greater profits. Marketing managers seeking maximum profits from selling a well-differentiated product on a downward sloping curve would find it unusual to have their current price on the inelastic portion of the demand curve. The price for achieving maximum profits is always greater than or equal to the price that maximizes revenues. It is far more common to find prices on the elastic portion of the demand curve and it is when demand is elastic that inconsistencies between increasing revenues and profits are found. The inconsistency of price elasticity for predicting the profitability of a price change leaves elasticity with some academic value and little practical application. There would be a much greater use for estimates of the current price elasticity if the price elasticity could consistently guide price changes towards larger profits.

Modern marketing managers need improved metrics for pricing products and optimizing their marketing mixes (Farris et.al., 2007; Davis, 2007). There is a need for a metric to guide managers in making price adjustments that move towards increased profits. The purpose of this paper is to present a metric that helps managers use the current estimates of the price elasticity and the markup to make profitable price adjustments.

\section{CLASSIC RELATIONSHIPS BETWEEN PRICE, ELASTICITY, REVENUE AND PROFIT}

The student explorations of price elasticity on the Internet have given me the opportunity to present the theory of optimal prices for maximizing revenue and maximizing profit. Students learned that when a manager has a 
complete description of the demand curve, then he can calculate the price that maximizes revenue and the price that maximizes profit. I was able to demonstrate that if the students had known that the demand curve for the problem was completely defined by the equation:

$\mathrm{Q}=1,000-100 \mathrm{P}$

where:

$\mathrm{Q}=$ the quantity sold,

$\mathrm{P}=$ the selling price,

then they could have easily calculated the price for maximizing revenue, $\operatorname{Pr}^{*}=\$ 5$ per unit and the price for maximizing profit, $\mathrm{Pz}^{*}=\$ 6$ per unit. If you have estimates of the complete demand curve, then estimates of price elasticity are irrelevant to the problem of finding optimal prices (Kotler, 1971).

However, a numerical example helps the students understand that the price that maximizes revenue, $\operatorname{Pr}^{*}$, on a linear demand curve is where elasticity is equal to -1.0 and that the price that maximizes profit, $\mathrm{Pz}^{*}$, is always greater than or equal to the price that maximizes revenue (Figure 1).

Most students can deal with the fact that both revenues and profits are quadratic in nature. That is to say, students can deal with the example of revenues and profits rising and then falling as the selling price is increased. The numerical example supports the student's intuitive view that when prices are increasing, revenues are increasing and profits will be increasing when the demand is inelastic. When the demand is inelastic, then profits move in the same direction as revenues (Figure 1).

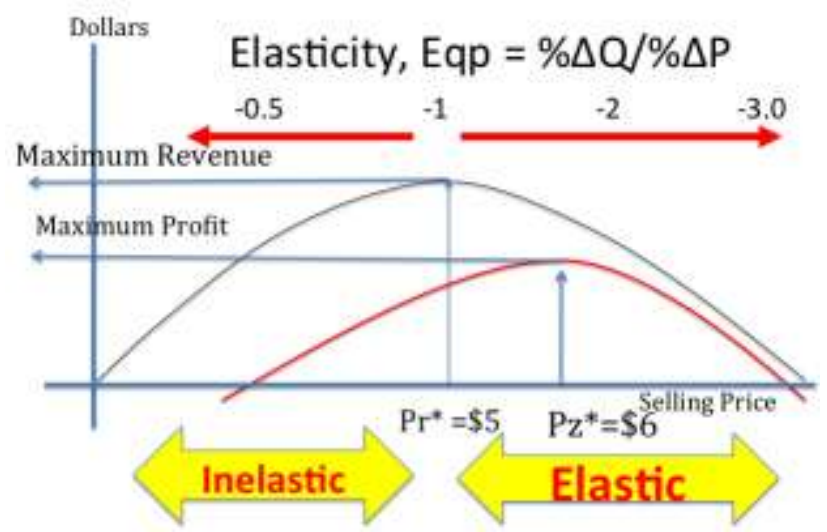

Figure 1: Prices that Maximize Revenue and Profit

However, the intuitive idea that revenues and profits should move in the same direction is not supported when the elasticity of demand is elastic. The great conceptual difficulty for most business students is to understand that there is a range of increasing prices over which the revenues are falling but the profits are still rising. When demand is elastic then there is a range over which selling prices can increase, revenues will decrease and profits will increase. Pricing scenarios in which profits decrease while revenues are increasing are counter-intuitive to most students. Price elasticity is a consistent predictor of the relationship between changes in price and changes in revenue. Price elasticity is an inconsistent predictor of the relationship between price changes and changes in profit.

Knowledge of the demand curve (i.e., the customer response to price changes) is sufficient to understand how changes in the selling price change the amount of revenue being generated. However, to understand how changes in price cause changes in the gross profit, then it is necessary to have information about the marginal costs of production. The importance of the marginal cost of the product (i.e., variable cost per unit) in calculating the price that maximizes profit is simple to demonstrate when the optimal price for maximum profit, $\mathrm{Pz}^{*}$, is calculated to be 
the price that maximizes revenue, $\mathrm{Pr}^{*}$, plus half the variable cost per unit (i.e., $\mathrm{Pz}^{*}=\mathrm{Pr}^{*}+\mathrm{V} / 2$ ). Furthermore it is easy to demonstrate that because the price that maximizes revenue occurs when the price elasticity is equal to -1.0 , then the price that maximizes profit must always be associated with a price elasticity that is equal to, or be a bigger negative number than -1.0 (Figure 1).

\section{PRICE ELASTICITY OF DEMAND AND MAXIMUM PROFIT}

Economists have proven that there is a relationship between price elasticity and the price that maximizes profit (Lerner Index of Monopoly Power, Lerner 1944). The relationship is discussed in many intermediate textbooks on the economics of pricing (Perloff, 1999, Pindyck and Runbinfeld 2005). The relationship between price elasticity and profit hinges on the marginal cost of production (i.e. the variable cost per unit, V).

The relationship between the price that maximizes profit, $\mathrm{Pz}^{*}$, and the price elasticity of demand, Eqp, at the optimal price is presented as:

$\mathrm{Pz}^{*}=\mathrm{V} /(1+(1 / \mathrm{Eqp})$

A key assumption to economists in the equation is that the marginal cost of production is constant. Most economists work with the assumption that marginal costs are increasing and many would find the relationship using a constant marginal cost of little interest. The relationship is usually presented as an interesting index for examining monopoly power. However, it has little application for managers setting prices because it does not lead to a direct calculation of the price that maximizes profit.

The difficulty is that the equation describing the relationship between elasticity and optimal price is true only when the current price, $\mathrm{P}$, is the optimal price, $\mathrm{Pz}^{*}$, for maximum profit. Some economists, such as Pindyck and Runbinfeld (2005), present the relationship as a means for checking "whether a particular output level and price are optimal." Unfortunately, there is nothing in the equation that suggests any guidance for the marketing manager seeking to adjust the current price towards higher profits. "The manager who correctly chooses the profit maximizing markup given the unit variable costs either has a good feel for demand conditions in the market or has made a lucky guess" (Truett and Truett, 1980, p. 194).

Although markup pricing is presented in every marketing textbook, it appears that marketers have totally ignored the economists' equation as a practical tool for profitable pricing. However, marketing managers have a need for something more than a lucky guess when adjusting prices. Marketers need a simple pricing metric that will predict when a small price increase will increase profits and when a small price increase will decrease profits. The relationship of price elasticity to optimal markup allows us to create a practical and consistent guide for adjusting prices towards higher profitability.

\section{THE OPTIMAL PRICING GUIDE, OPG}

The Optimal Pricing Guide, OPG, is a metric that can help marketing managers adjust the selling price in the direction of greater profits. It starts with a modified version of the Pindyck and Rubinfeld equation (2005, $\mathrm{p}$. 348 ) and builds on the fact that the optimal price, $\mathrm{Pz}^{*}$, for maximizing profit has been established when the following equation is true:

$1 / \mathrm{Mp}=|\mathrm{Eqp}|$

where:

$\mathrm{Mp}=(\mathrm{P}-\mathrm{V}) / \mathrm{P}=$ the markup on price

$\mathrm{P}=$ the selling price per unit

$\mathrm{V}=$ the variable cost per unit (i.e., a constant marginal cost per unit)

$(\mathrm{P}-\mathrm{V})=$ the profit per unit sold where $\mathrm{P}>\mathrm{V}$

$|\mathrm{Eqp}|=$ the absolute value of the price elasticity of demand 
However, it is the difference between the absolute value of the price elasticity and the inverse of the markup that makes the relationship a practical metric. We define the difference between the inverse of the markup and the absolute value of the price elasticity to be the optimal price guide, OPG. That is to say,

$\mathrm{OPG}=1 / \mathrm{Mp}-|\mathrm{Eqp}|$

There are three possible solutions to the equation that make the OPG a practical aid for adjusting a current price towards greater profitability:

1. A Positive OPG: If the difference between the inverse of the markup and the absolute value of the elasticity is positive, $1 / \mathrm{Mp}$ - $|\mathrm{Eqp}|>0$, then the OPG is positive and a small increase in price will increase profits.

2. A Negative OPG: If the difference between the inverse of the markup and the absolute value of the elasticity is negative, $1 / \mathrm{Mp}-|\mathrm{Eqp}|<0$, then the OPG is negative and a small decrease in price will increase profits.

3. An OPG equal to Zero: If the difference between the inverse of the markup and the absolute value of the elasticity is equal to zero, $1 / \mathrm{Mp}-|\mathrm{Eqp}|=0$, then the $\mathrm{OPG}$ is zero, the price that maximizes profit is reached and any change in selling price will reduce the gross profit.

It is the basic relationship between the markup on price and the price elasticity to changes in the selling price that provide the argument for making a price adjustment towards the optimal price.

\section{Changes in Markup on Price, Mp, with Changes in Price}

Markup on price is one of the most important metrics in cost-based pricing management. Markup on Price, $\mathrm{Mp}$, is defined as a ratio of the dollar markup (i.e., profit margin per unit) over the selling price. The inverse of the markup is

$1 / \mathrm{Mp}=\mathrm{P} /(\mathrm{P}-\mathrm{V})$

For the purposes of this discussion, we assume that the profit margin, $\mathrm{P}-\mathrm{V}$, is always positive (i.e., the selling price, $\mathrm{P}$, is greater than the variable cost per unit, $\mathrm{V}$, ) and that the variable cost per unit represents a constant marginal cost.

A dominant characteristic of the markup on price ratio is that when the price increases and the variable cost is held constant, then the value of the ratio moves closer and closer to 1.0 or $100 \%$. When the price, $\mathrm{P}$, is very low, then the profit margin, $\mathrm{P}-\mathrm{V}$, is very small. When the profit margin is very small, then the inverse of the markup is a very large positive number. When the selling price increases then the inverse value of the markup becomes smaller and approaches unity (Figure 2). For the markup to be equal to unity, $1 / \mathrm{Mp}=1$, then the variable cost must be equal to zero, $\mathrm{V}=0$. As discussed above when the variable cost is equal to zero, $\mathrm{V}=0$, then the price that maximizes revenue is equal to the price that maximizes profit.

\section{Changes in Elasticity, Eqp, with Changes in Price}

Price elasticity is a negative index reflecting the fact that a price decrease results in an increase in the quantity sold. However, it is common for economists to avoid the negative nature of price elasticity and use the absolute value of the index when discussing price sensitivity. The most important characteristic of using the absolute value of price elasticity is that its value starts at zero when the price is zero and becomes a larger and larger number as the selling price increases (Figure 2). When the price reaches the optimal level for maximizing revenue, Pr*, then the absolute value of elasticity is equal to unity, $|\mathrm{Eqp}|=1$. When there is a variable cost greater than $0, \mathrm{~V}>0$, then the price that maximizes profit, $\mathrm{Pz}^{*}$, is greater than the price that maximizes revenue, $\mathrm{Pz}^{*}>\mathrm{Pr}^{*}$. 


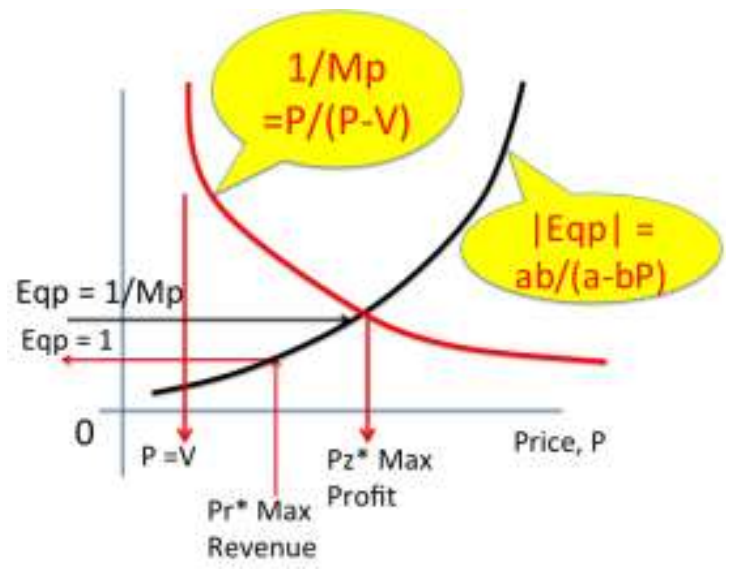

Figure 2: The Optimal Pricing Guide

When the price increases to the optimal level for maximizing profit, $\mathrm{Pz}^{*}$, then the absolute value of the price elasticity is equal to the inverse value of the markup,

$1 / \mathrm{Mp}=|\mathrm{Eqp}|$

Figure 2 shows that when the price is lower than the price that maximizes profit, $\mathrm{P}<\mathrm{Pz}^{*}$, the value of the inverse markup is greater than the absolute value of the price elasticity $(1 / \mathrm{Mp})>|\mathrm{Eqp}|$ and the optimal pricing guide is a positive number. When the optimal pricing guide is positive, $\mathrm{OPG}>0$, then a small price increase will increase profits.

When the price is higher than the price that maximizes profit, $\mathrm{P}>\mathrm{Pz}^{*}$, then the value of the inverse markup is less than the value of the price elasticity, $1 / \mathrm{Mp}<|\mathrm{Eqp}|$, and the optimal pricing guide is a negative number. When the optimal pricing guide is negative, $\mathrm{OPG}<0$, then a small price decrease will increase profits.

\section{Using the Optimal Pricing Guide, OPG}

Using the difference between the inverse value of the current markup and the absolute value of the elasticity at the current price is a simple guide to optimal pricing. It is the direction of the sign of the OPG (i.e., positive or negative) and not magnitude of number that provides the value in the application. The size of the difference depends on the size of the variable cost and the sensitivity of the customers to a price change. It would be a mistake to assume that a larger OPG implies the need for a larger price change to reach the optimal price.

The OPG is a metric that makes estimates of the price elasticity more relevant to the manager seeking to adjust to a more profitable selling price, but is no panacea. The classic forces that drive changes in the current price are still in play. Forces such as market growth, customer psychology, the relative prices of the competitors, changes in the firm's costs all play their traditional roles in the decision process. The optimal pricing guide simply makes a small piece of economic theory more relevant in an age where more emphasis is being placed on marketing metrics. Metrics, such as the proposed OPG, that are soundly rooted in theory of marketing and economics should serve the manager better than rules of thumb with no logical support.

\section{AUTHOR INFORMATION}

Ted Mitchell, Ph.D., Associate Professor, College of Business, University of Nevada, Reno, NV 89434 USA. Telephone: 775-356-6234. E-mail: Theodorem@unr.edu (Corresponding author)

Igor Makienko, Ph.D., Assistant Professor, College of Business, University of Nevada, Reno, NV 89434 USA. E-mail: Imakienko@unr.edu 
Shawn Mitchell, BA, MA, President of Chessboard Communications, Sparks, NV 89434 USA. E-mail: Shawn@shawnpmitchell.com

\section{REFERENCES}

1. Davis, John, 2007, Measuring Marketing: 103 Metrics Every Marketer Needs. John Wiley and Sons Pte, Ltd. Singapore.

2. Farris, Paul W., N.T., Bendle, P.E Pfeifer, and D.J. Reibstein. 2006, Marketing Metrics: 50+ Metric Every Marketing Manager Should Master, Pearson Education, Inc. publishing as Wharton School Publishing, Upper Saddle River, NJ.

3. Kotler, Philip. 1971, Marketing Decision Making: A Model Building Approach, Holt, Rinehart and Winston, NY.

4. Lerner, A.P. 1933-34a, "The Diagrammatical Representation of Elasticity of Demand," Review of Economic Studies, I(1): 33-34.

5. $\quad$ Perloff, Jefferey M., 1999. Microeconomics, Addison Wesley Longman, Inc., Reading, Mass.

6. Pindyck, Robert S., and D.L. Rubinfeld, 2005, Microeconomics, Pearson Prentice Hall, Upper Saddle River, NJ.

7. Truett, Lila J., and Dale B. Truett, 1980, Managerial Economics, South-Western Publishing Co., Cincinnati, Ohio.

8. Wiki answers.com, http://wiki.answers.com/Q/If_you_were_a_business_owner_how_would_you_use_price_elasticity_of_dem and_to_determine\#ixzz209RRy9CU 
NOTES 